\title{
Arbor
}

\section{Familia y trabajo de la mujer}

\author{
Julio Iglesias de Ussel
}

Arbor CLXXVIII, 702 (Junio 2004), 167-185 pp.

\section{Introducción}

Un interesante utopista del XIX, Fourier, formuló una acertada apreciación sobre la dinámica histórica. Vinculaba la evolución de la sociedad, directamente, a la situación de la mujer, al escribir que: «Los progresos sociales y los cambios de fases históricas se producen en razón del progreso de las mujeres hacia la libertad, y las decadencias de orden social se operan en función de la limitación de la libertad de las mujeres» («Theorie des Quatre mouvements» vol. 1. ${ }^{\circ}$, ed. Anthropos, Paris, 1966 pag. 130). Su juicio se adelantó a la historia y tardó en hacerse realidad. Pero si en el futuro merecemos la atención de los historiadores, sin duda el siglo XX será juzgado muy positivamente por el cambio de la situación de las mujeres en las sociedades desarrolladas occidentales. La aceleración histórica ha sido simultánea a su plena incorporación al trabajo, al sistema educativo y a las esferas de poder. Esta vinculación establecida por Fourier del movimiento de la historia en función de la situación de mujer, incide de manera notoria en el examen de la relación entre familia y trabajo.

Esa misma dicotomía que muchas veces se contempla entre vida familiar y trabajo extradoméstico, o el planteamiento de los efectos del trabajo de la mujer en la familia pueden ser enfoques analíticos adecuados; la realidad social hay que trocearla para escudriñar sus características. Pero la familia no es causa ni efecto del trabajo. Sus lógicas se encuentran imbricadas. Podemos y debemos en ocasiones analizarlas por separado, pero lo importante es tomar constancia que ninguna puede existir sin la otra. Son las dos caras de la misma moneda. El trabajo supone la familia y, recíprocamente, la familia supone el trabajo. Ninguno puede existir sin el otro, de ahí el acierto de estudiar conjuntamente familia y 
trabajo. El libro de Barrere Maurison («La división familiar del trabajo» 1999) es muy acertado en este planteamiento.

Pero conviene hacer otra precisión previa. Es usual repetir que «las mujeres se están incorporando al trabajo». Se trata de una afirmación que rueda incesantemente y que todos -yo incluido, desde luego- hemos sostenido o deslizado en alguna ocasión. Se trata de un juicio que acierta, al resaltar los cambios en la población activa; pero si analizamos con precisión el pasado ese juicio es erróneo. Históricamente en las sociedades agrarias siempre han trabajado las mujeres, con la misma eventualidad, con la misma temporalidad derivada de las circunstancias climatológicas, del ciclo agrario, de las posibilidades de riegos etc. que los varones. En estas sociedades, muchas veces basadas en el autoconsumo y el trueque, ha sido siempre toda la sociedad -incluidos también los niños- la que ha estado involucrada en la actividad laboral y la obtención de medios de subsistencia. Quizá con mayor intensidad y responsabilidad los adultos varones, pero nadie quedaba excluido de colaborar en la subsistencia del grupo. Toda la familia ha sido una pieza esencial para la obtención de medios y recursos; incluso hoy mismo en España nadie ignora la presencia de los niños en determinadas actividades agrícolas, como en la recolección de aceituna entre otras. Las mujeres pues siempre han trabajado con la misma eventualidad que lo hacían los varones y su aportación a la supervivencia económica del grupo familiar ha sido siempre decisiva.

La fortaleza de esta apreciación sobre la ausencia de la mujer del trabajo, tiene unas raíces próximas en el tiempo. Se trata de un fenómeno vinculado con la Revolución Industrial. Entre otros muchos cambios sociales imposibles de analizar ahora, la Revolución Industrial ocasionó la separación del hogar y del trabajo en ámbitos espaciales diferenciados y, lo que fue todavía más relevante, la imposibilidad de simultanear las actividades laborales con las domésticas, incluyendo las de contenido económico como el cuidado de animales domésticos. Entonces es cuando se produce el trasvase de actividad laboral de la mujer -al igual que de los niños- a las nuevas fábricas, alejadas de sus domicilios y con jornadas rígidas de trabajo. La industrialización nació con nombre también de mujer, por mucho que se quiera ocultar.

Los historiadores han analizado los efectos de la incorporación al moderno sistema fabril, con jornadas de trabajo extenuantes, de las mujeres y niños. La quiebra de los ritmos vitales de la sociedad agraria, al igual que la aparición de la productividad por tiempo de trabajo -en el mundo agrario era innecesario la prolongación del tiempo de trabajo una 
vez hechas las actividades debidas-, modificó por completo las condiciones de vida de la población. Toda la literatura romántica del XIX contiene una exaltación de la palidez de la mujer que es testimonio de los nuevos valores burgueses que priman la ausencia de la mujer del trabajo y su confinamiento en la esfera doméstica, la ausencia de contacto con el exterior. Si encontrarse moreno es hoy el símbolo del ocio, la palidez era entonces la manifestación de la ociosidad, de ocupar posiciones sociales privilegiadas y de encontrarse fuera de la actividad laboral. Fue entonces cuando se organiza el discurso orientado a exaltar el encapsulamiento doméstico de la mujer -en el que los médicos tuvieron gran protagonismo-, cuando atravesaban las peores experiencias laborales de la historia, al igual que los niños.

Se debe pues subrayar que históricamente siempre han trabajado las mujeres. Por eso cuando decimos que hoy se incorporan las mujeres al trabajo, estamos excluyendo el trabajo no remunerado que ha sido a lo largo de la historia instrumento decisivo para la supervivencia de las familias y parte esencial de la vida de la mujer. La actividad del hogar, asentada fundamentalmente en el trabajo de la mujer, con un importante componente monetario directo o indirecto, era esencial para la supervivencia del grupo. Hoy que ha sido analizado ya todo ese enorme iceberg de tareas no remuneradas, se ha evidenciado que ha sostenido siempre la vida nacional.

Igualmente, al afirmar la incorporación de la mujer al trabajo, estamos ignorando o minusvalorando el papel de la mujer en el medio rural en la actualidad. Aunque persisten arraigados tópicos sobre su retraso, el dinamismo del medio urbano no puede hacer desconocer los acelerados cambios también el medio rural. En el 2001, seis millones de personas habitan en núcleos de menos de 10.000 habitantes. Y según el último Censo Agrario, medio millón de mujeres son titulares de explotaciones agrarias españolas. Pero el empleo en el medio rural cada vez está menos vinculado a la agricultura. La terciarización de su actividad económica es un hecho como lo prueba que del total de mujeres ocupadas, el $67,7 \%$ lo están en el sector servicios. Y si a ello se añade que se estima que en España hay cerca de un millón de mujeres. que colaboran en las explotaciones como ayuda familiar, pero no están incluidas en las estadísticas, nos ofrece un panorama muy lejano a la falta de relevancia del empleo de la mujer en el medio rural. La actividad de la mujer es también mucho más alta de lo que se suele dar por hecho desde él medio urbano. (Vease sobre esto: CES: «Panorama sociolaboral de la mujer en España» N. $\left.{ }^{\circ} 32,2003\right)$. 
En relación a la situación anterior a la democracia, deben mencionarse algunos cambios relevantes. Desde la década de los sesenta se ha incrementado notablemente la incorporación de la mujer al trabajo extradoméstico, sobre todo desde 1996. Son muy numerosos los factores que han influido tanto privados, como sociales desde económicos, ideológicos, oportunidades laborales, esperanza de vida, etc. Pero conviene mencionar algunos rasgos singulares de este proceso.

1. En la democracia las mujeres se incorporan al mercado de trabajo con más edad. En el franquismo accedían menos mujeres, pero las que accedían se incorporaban muy jóvenes.

2. En segundo lugar, hoy se incorporan al mercado de trabajo con niveles educativos más elevados que los varones. Como pone de relieve la Encuesta Sociodemográfica del INE, cuentan con más años de estudios que los varones.

En España, como en otros países, el incremento del nivel educativo de la mujer ha sido un factor de atracción decisivo. Quien sabe si las dificultades históricas para que la mujer estudiase en España tenían como objetivo oculto impedir que las mujeres se incorporaran al mercado de trabajo. Porque el hecho es que la tasa de actividad crece con el nivel educativo. Y España es el país de la Unión Europea de los 12, con más alta proporción de mujeres con estudios universitarios, en los grupos de edad de 25 a 34 años, después tan solo de Finlandia y Bélgica. Una circunstancia que influye de doble manera: ha aumentado la oferta de empleos cualificados aptos para ser desempeñados con personas con estudios y por otra parte, al ser empleos con mayor cualificación y salarios, atraen empleo de la mujer y, sobre todo, la retienen dentro del mercado de trabajo, sin excedencias ni abandonos.

3. Al incorporase con más edad y con mayor nivel educativo, lo hacen en puestos de trabajo con un nivel retributivo más elevado que lo hacían en el pasado.

4. Y como consecuencia, un cambio básico y determinante en nuestra vida social y en el análisis de la relación entre trabajo y familia. Me refiero a que las mujeres se incorporan pero ahora con plena continuidad laboral. Se trata de una dimensión esencial y que ha cambiado radicalmente en relación al franquismo. La mujer se incorpora hoy al trabajo pero para hacer una carrera profesional. Por consiguiente la novedad en relación a nuestro pasado no es que la mujer trabaje hoy y en el pasado no. La novedad no es que hoy entren en el mercado, sino que no salen, que es muy distinto.

En el franquismo, la mujer se integraba -en menor número- en el mercado de trabajo, pero muy joven y sin estudios y por tanto en puestos 
con bajas retribuciones. Pero por mandato legal o por costumbres sociales o por todo al mismo tiempo, entraban pero luego salían o las hacían salir. Por eso la diferencia es que antes salían y ahora no; ahí está el cambio radical con consecuencias de todo orden en nuestra vida colectiva. Hoy se incorporan con la misma voluntad de permanencia o continuidad o vocación o para ganarse la vida como lo hacen los varones. Son una variedad de heterogéneas razones las que mantienen dentro de las estructuras laborales a los ciudadanos.

$\mathrm{Y}$ esta novedad se ve reforzada, como entre los varones, a causa del paro y del temor a encontrarse con dificultades para retornar un empleo si se abandona voluntariamente. El paro y la sensibilidad ante el paro, que no es lo mismo, generan rigideces en el mercado de trabajo, reduciendo muy considerablemente los flujos voluntarios de entrada y salidas. Conseguido un empleo, se mantendrá indefinidamente, salvo encontrar otro más gratificante. Pero quedan excluidas otras opciones como salir para mejorar la formación o el abandono por insatisfacción. El paro hace tan rígida la entrada como la salida del empleo.

Se trata de una situación relevante para nuestra reflexión. Esto quiere decir, que en situación de crisis de empleo ni los padres ni las madres se muestran proclives a prolongar su alejamiento del trabajo, más allá de las licencias legales. Pero se renuncia a alargar los períodos de cuidado de los niños con excedencias o permisos, porque el temor a dificultades de retorno al empleo mantiene dentro a personas que estarían fuera con otras expectativas.

\section{Trabajo de la mujer y mercado de trabajo}

El dinamismo de nuestra sociedad ha producido cambios significativos en el mercado laboral. Por eso si hablamos de toda la sociedad española, las desigualdades o falta de equidad es notoria, pero si tratamos de las cohortes generacionales jóvenes la situación es mucho menos discriminatoria. La conquista de la equiparación está mucho más próxima en las generaciones jóvenes que en las adultas. Por eso queda por suceder, en el futuro inmediato, un cambio, por decirlo gráficamente: que manden mujeres viejas, como lo hacen hoy hombres viejos en la magistratura, en la universidad, la medicina, el periodismo, la política, la empresa y en cualquier otro ámbito social. Hoy esas mujeres son minoría, porque fueron muy minoritarias quienes pudieron acceder al empleo con altas cualificaciones -y continuar en el empleo- treinta o cuarenta años atrás. 
Pero desde la democracia ya no ocurre lo mismo. Y por eso será cada vez más habitual la accesibilidad de mujeres mayores hasta altos niveles ocupacionales y a la cúspide de sus carreras profesionales. Y en algunas profesiones ocurrirá lo contrario: serán muy minoritarios los varones en los puestos más altos - por ejemplo, la judicatura o muchas carreras funcionariales- porque desde hace años son muy mayoritarias en el acceso las mujeres. Es una cuestión de tiempo. La mayoría de los notarios de Madrid serán mujeres, o los Magistrados de los Tribunales de mayor rango, cuando lleguen a la cima de sus carreras las promociones mayoritarias de mujeres.

Igualmente hay que mencionar que haya sido alta o baja la presencia de la mujer en el mercado de trabajo, éste ha sido siempre segregado.

1. La mayoría de los empresarios son varones (73,5 por ciento).

2. Entre los asalariados, son mayoría los varones (60,6 por ciento). Pero esa desigualdad es resultado de una situación presente sobre todo en el sector privado donde hay un $62,8 \%$ de varones. Sin embargo en el sector público sí hay una situación de equilibrio: $48,3 \%$ de mujeres y $51,6 \%$ de varones. En todos los países, el sector público cuenta con tasas elevadas de empleo de mujeres; sea por su mayor flexibilidad, por las políticas públicas o por las mayores presiones sindicales, el caso es que el sector público ha sido casi siempre el sector de vanguardia en el empleo de mujeres. Incluso históricamente, el sector público o parapúblico -piénsese en las telefonistas o en las cigarreras de las fábricas de tabaco- ha incorporado a mujeres con adelanto sobre el sector privado.

3. Sus diferencias internas han sido tan acusadas como las externas. Las mujeres siempre han sido muy minoritarias en ciertos sectores ocupacionales (la agricultura, la construcción o la minería por ejemplo) y también en otros casi siempre han sido mayoritarias. Donde hay cierta equidad es en el sector servicios donde el $51,4 \%$ son varones y el $48,6 \%$ son mujeres. Entre 19 categorías del INE, las únicas donde la mayoría son mujeres son la del Resto del personal administrativo y comercial y Resto del personal de servicios (Ine: «Hombres y mujeres en España» Madrid 2003). Añadiré que las mujeres son mayoría en sectores en expansión, mientras que tienen muy escasa presencia en sectores con pérdida de empleo: agricultura, industria, minería etc, donde los varones son claramente mayoritarios.

4. Otra precisión que debe hacerse es la naturaleza del trabajo a tiempo parcial o a tiempo completo. Siempre se destaca que la tasa de actividad de la mujer en España es inferior a la que prevalece en Europa de los 12. Es cierto, pero sobre todo por la menor actividad de las mujeres de más edad; entre las más jóvenes las pautas son análogas a las de países más de- 
sarrollados. Pero lo que no se destaca suficientemente es que en España está muy poco extendido el empleo a tiempo parcial. En éste son mayoría en España las mujeres. Es notablemente mayor el porcentaje de las mujeres entre los ocupados a tiempo parcial, el 79,8\%, mientras que la mayoría de los ocupados a jornada completa son varones: el 66\%. Problema diferente que no es posible abordar aquí es el grado de voluntariedad de quienes trabajan a tiempo parcial; probablemente es más alto en España el porcentaje de quienes lo hacen a falta de otra oportunidad laboral.

5. Si nos fijamos únicamente en la realidad laboral pero solo de las parejas con hijos, la situación española es diferente a la predominante en la Unión Europea de los 12. España contaba en el año 2000 el porcentaje más alto de parejas con un solo sustentador económico (56,3\%); Irlanda, Italia y Luxemburgo el porcentaje supera también a la mitad. En España trabajan los dos miembros en el $43,7 \%$ de los hogares con niños. Pero en el caso de que ambos miembros de la pareja estén ocupados, en ningún país era frecuente que la mujer trabajase a tiempo completo y el hombre a tiempo parcial; sucedía en España en el 0,4\% de los casos pero no llega al $2 \%$ en ningún país. Los porcentajes son iguales de reducidos en el supuesto de si los dos trabajan a tiempo parcial; ocurre en el 0,2\% de los hogares con hijos en España. La situación más frecuente, en general, es que los dos trabajen a tiempo completo, lo que ocurre en España en el 35,6\% de estos hogares con hijos. Y le siguen en frecuencia cuando el varón trabajo a tiempo completo y la mujer a tiempo parcial que sucede en el 7,5\% de los casos en España (CES: Panorama sociolaboral de la Mujer en España, 28, 2002).

Las diferencias retributivas existen y son significativas, pero su análisis requiere ponderar los datos en función de la duración de la jornada, antigüedad en el empleo, nivel ocupacional o los componentes retributivos incluídos (pagas extraordinarias y otros), etc. Pero los datos globales, con toda su imperfección, son reveladores. Hace unos años, en 1998, la Unión Europea elaboró un estudio sobre las diferencias retributivas por sexo entre cuatro países. De la comparación de los salarios de las mujeres por hora de trabajo, se desprende que es en Suecia donde existe mayor igualdad salarial con el $84,0 \%$ del salario medio de los hombres, frente al 72,9\% en Francia; el 72,7\% en España y el 64,4 en el Reino Unido. Los resultados nos sitúan en una posición intermedia, debajo de Suecia, análogo a Francia y mejor al del Reino Unido.

Por categoría profesional del trabajador, los cuadros profesionales y directivos es donde se produce mayor discriminación. Al examinar los datos por edad, se observa un hecho presente en otros muchos aspectos de nuestra realidad social: el cambio radical según generaciones. Aquí tam- 
bién se constata: Disminuye la discriminación retributiva a medida que se desciende en la edad, donde la discriminación salarial desciende mucho en los grupos de edad con menos de 30 años (CES: Panorama sociolaboral de la mujer en España» n. ${ }^{\circ}$ 13, julio 1998).

Estos datos de participación laboral ponen de relieve la importancia de analizar la cuestión no en términos de principios -trabajo sí, trabajo nosino en términos de balance laboral de la pareja o matrimonio (o incluso de todos los miembros del hogar). Pero en España debe advertirse el menor peso de la mujer en la población activa y también la menor presencia del trabajo a tiempo parcial. Y cuando hablamos de los efectos hay que hacerlo en función de las singulares condiciones laborales realmente existentes.

Cuando se piensa en el trabajo se tiene como marco de referencia el trabajo en el sector servicios en jornada, continuada o partida, a tiempo completo. Pero hay multitud de actividades sometidas a horarios y a ritmos temporales singulares. Y esto sin entrar en el componente espacial que pueda conllevar el trabajo. Me refiero a la necesidad de desplazamientos estables, pero duraderos, que pueden ser obligados en el puesto de trabajo que se desempeñe. Se trata del acceso a un puesto de trabajo en distinta localidad de la residencia del resto de la familia, y cuya distancia impida el reencuentro cotidiano del grupo familiar.

Y hay una dimensión que resulta esencial para verificar la relación trabajo mujer-familia. No es posible examinar esta relación en términos individuales. No es posible examinar la relación trabajo de la mujer-familia en términos dicotómicos: trabajo-no trabajo. Para captar sus vínculos se necesita no solo el conocimiento de la relación individual, sino la bolsa laboral con que cuenta la familia. No son idénticos los efectos de ese trabajo si coincide con la situación de paro, de jubilación, de trabajo del mismo nivel o más alto o más bajo por parte de su cónyuge, etc. Y lo mismo se puede decir en relación a la propia naturaleza del trabajo. No es lo mismo el trabajo nocturno, el de fin de semana, el trabajo en turnos rotatorios etc. a la hora de compaginar la vida familiar y las responsabilidades laborales. Lo que interesa realmente son las peculiaridades de la actividad laboral de la totalidad del grupo familiar donde se inserta el trabajo de la mujer y del varón.

\section{Acceso familiar al trabajo}

Otro hecho a destacar es que el trabajo de los dos miembros de la pareja constituye un componente básico del bienestar de la sociedad española. Sin la aportación económica de los dos sería bien difícil de man- 
tener los niveles de consumo de buena parte de los hogares. Pero la importancia laboral de la familia arranca de la propia génesis de la relación: el acceso al mercado de trabajo se realiza en buena parte gracias a las conexiones familiares y, en general, particularistas. Incluso en convenios colectivos existen cláusulas que favorecen el acceso a la empresa cuando son familiares de personas que ya pertenecen a la empresa. En todo caso, y como ya mostró un trabajo de Felix Requena, es extraordinariamente frecuente que se acceda a un empleo donde ya se encontraba trabajando algún familiar (13\%) o algún amigo (11\%); en conjunto una de cada cuatro personas accedían por conductos particularistas (en «Determinantes estructurales de las redes sociales en los hombres y las mujeres» Papers, n. ${ }^{\circ}$ 45; 1995 pag. 37).

\section{Endogamia ocupacional}

Si el ingreso en el mercado de trabajo se encuentra mediatizado por la realidad familiar, los efectos del trabajo en la familia se producen en primer lugar en la nupcialidad. Existen numerosas evidencias de las altas tasa de endogamia en España. El mercado de trabajo es mercado, también, matrimonial. La proximidad favorece el establecimiento de alianzas y compromisos interpersonales. Aunque la norma ideal de las sociedades occidentales establece que cualquier persona puede casarse con cualquier otra - no hay sectores excluidos en abstracto-, en la práctica la elección de pareja se produce entre los próximos. Y esa proximidad se produce en el mercado laboral, al igual que en las Universidades.

Los intereses se concretan con el contacto en espacios determinados, como el laboral. El influjo de estos escenarios en el matrimonio posiblemente sea más alto en los segundos matrimonios que en los primeros, pero no hay datos suficientes para avalarlo. En conjunto, entre 1994 y 2000, la endogamia profesional es muy alta y permanece estable. En la categoría de Profesionales técnicos y trabajadores asimilados, el $48 \%$ de las esposas se casan con esposos de la misma profesión. Y el porcentaje asciende aún más en sectores como Trabajadores de la producción y asimilados $(66,87 \%)$, profesionales de las fuerzas armadas $(53,82 \%)$. En el conjunto de todas las categorías profesionales la endogamia profesional asciende a $33,93 \%$ en el año 2000 , con un muy leve crecimiento en los últimos seis años (INE: Indicadores Sociales 2003, pag. 301). 


\section{Trabajo y tasa de nupcialidad}

Pero la relación del trabajo con la nupcialidad no se limita a la elección de pareja, abarca también a su frecuencia. El mercado de trabajo repercute en la formalización de uniones matrimoniales. La crisis de empleo y las elevadas tasas de paro de los años 80 y 90 , han afectado imposibilitando la formación de parejas y/o retrasando los proyectos. Sin duda, una buena parte del descenso continuado desde 1975 de las tasas de nupcialidad ha de atribuirse a la crisis de empleo en el mercado laboral. Casarse y tener hijos, son decisiones y compromisos esencialmente de futuro. Por consiguiente cuando se perciben incertidumbres en ese futuro, en torno a la estabilidad o seguridad en el empleo, esos proyectos de futuro se retrasan o en todo caso se perturban.

La pauta mayoritaria de la sociedad española establece que para contraer matrimonio, el varón ha de tener trabajo y, si es posible, también la mujer. Pero la situación inversa es contemplada tal vez sin censuras, pero sin entusiasmo. Y esto es lo que ocurre efectivamente en la mayoría de los casos. En un estudio realizado por Alberdi, Flaquer e Iglesias de Ussel, examinamos las parejas en relación con el empleo de los respectivos cónyuges en el momento de formar el primer hogar. Encontramos que en la mitad de los casos (50,9\%) trabajaba tan sólo el varón; en un 40,8\% trabajaban ambos cónyuges; en el 5,4\% no trabajaba ninguno de ellos y el porcentaje más bajo, en un 2,9\% de los casos, tenía empleo la mujer pero no el varón («Parejas y matrimonios: actitudes, comportamientos y experiencias» 1994 pag. 66). Sin embargo ha de advertirse que aunque estas sean las tendencias mayoritarias, cada vez son menos acusadas las censuras cuando se produce la situación inversa: la mujer con trabajo y el varón sin él, sobre todo si esa situación deriva de la falta de oportunidades o se compagina con ampliación de formación o estudios.

\section{Trabajo y celibato}

Históricamente el individuo aislado tenía muy difícil supervivir. La familia era una unidad organizativa imprescindible para hacer frente a las necesidades de la vida cotidiana y sus emergencias, fueran estas la enfermedad, la ancianidad o la incapacidad laboral. No era posible sobrevivir sin el apoyo del grupo. Por esto siempre hubo escasa soltería que, además, estaba estigmatizada porque, en efecto, quienes quedaban fuera del mercado matrimonial con frecuencia contaban con defectos o 
carencias significativas. Incluso las muy altas tasas de viudedad a edades tempranas, eran acompañadas con tasas igualmente altas de segundos matrimonios.

Este escenario ha desaparecido por completo. Hoy el matrimonio constituye una opción real para los ciudadanos, y nada les obliga a vivir en familia si prefieren hacerlo en solitario. El matrimonio, ahora sí, constituye una elección personal. Y en esta dirección, el acceso creciente de mujeres a niveles ocupacionales y retributivos altos, esta ocasionando tanto el aumento de mujeres que postergan hasta edades muy tardías sus proyectos matrimoniales, también aumentan las cohabitaciones en esos niveles ocupacionales o, en definitiva, la soltería definitiva. De paso debe destacarse que este nuevo escenario fundado en la existencia de libertad de elección, refuerza la relevancia de la nupcialidad que se produce hoy. Ha cambiado radicalmente el entorno, pero la mayoritaria aspiración social se orienta a configurar los proyectos vitales en el matrimonio o en la cohabitación.

Es decir, el trabajo altera los escenarios vitales pautados o estandarizados del pasado. Ha ampliado la heterogeneidad de las opciones vitales, con repercusión en las opciones matrimoniales.

\section{Matrimonios a distancia por razón de trabajo}

El creciente acceso de la mujer al mercado de trabajo -que además no abandona por tener las mismas aspiraciones de carrera y promoción que los varones-, ha hecho aparecer el fenómeno del trabajo separado del marido y de la mujer en provincias separadas, incluso lejanas que permiten únicamente encuentros de fin de semana, y a veces ni eso. Se trata de un fenómeno nuevo, al menos en la magnitud que ya se constata.

Siempre han existido ocupaciones que ocasionaban la separación y distancia entre la pareja. Piénsese, por ejemplo, en los marinos que pescan en lejanos caladeros durante largas temporadas, entre otras muchas ocupaciones. Pero lo que se trata ahora es de personas que cada una tiene un empleo fijo en localidades diferentes y distantes. Hasta ahora en determinadas profesiones de la administración pública se hacía frente a la situación, concediendo un derecho preferente de traslado al cónyuge, para favorecer el reagrupamiento; era el llamado derecho de consorte que existía, por ejemplo entre los maestros, ocupación de siempre muy feminizada.

Pero este fenómeno no solo ha crecido en otros ámbitos de la administración pública, sino en la empresa privada. Son matrimonios que 
bien pueden llamarse como «matrimonios a tiempo parcial» por la permanente separación, acompañada de cortos semanales reencuentros.

¿Cómo funcionan estos matrimonios separados por el trabajo? Depende de muchas variables. Una, muy importante, es la perspectiva de futuro en que se ubica la situación de separación, la percepción de su transitoriedad o estabilidad. Esa consideración del futuro genera muy diferentes vivencias del presente. Pero otras dimensiones son igualmente básicas: el número de hijos, los ingresos, quien sea el desplazado si la mujer o el marido y los eventuales apoyos que puedan recibir uno u otro en los dos domicilios familiares, la duración de la separación, el momento de la vida de pareja en que se produce la separación y, claro está, la situación real en que se encuentre el matrimonio en el momento de la separación por motivo del trabajo. Se trata pues de una realidad muy compleja para resumir con una respuesta genérica. Pero una tesis doctoral que dirijo, de Roseta Rodrigo, parece avalar que no son negativas estas experiencias. Lo que reducen en cantidad, pueden incrementarlo en calidad sin llegar a cristalizar roces derivados de la vida cotidiana.

\section{Natalidad}

Desde siempre se ha dado por hecho que uno de los efectos más evidentes de la incorporación de la mujer al trabajo era la reducción de la natalidad. Pero las evidencias no siempre son eternas. La manifestación más clara la tenemos hoy a escala europea. Los países con más alta tasa de natalidad son los nórdicos, y son al mismo tiempo los que cuentan con las más altas tasas de incorporación de la mujer. Y viceversa: países como España o Italia con tasas de actividad de la mujer más bajas, tienen también menor natalidad. Luego la correlación entre trabajo y descenso de natalidad, dista de ser clara y se encuentra mediatizada por numerosas variables a tener en cuenta.

Las Encuestas de Fecundidad ponen de relieve en España el descenso de la natalidad y su vinculación con la actividad laboral, pero de manera bastante compleja. Por ejemplo en España esta creciendo la maternidad a edades avanzadas; no me refiero a edades que cabe interpretar como retraso en el calendario reproductivo, hasta 30 ó 34 años, en gran medida como consecuencia del retraso en el matrimonio. Pero en el grupo de edad entre 35 y 39 años se ha multiplicado por tres el porcentaje de nacidos entre 1975 y 1995; pasan de ser 2,3\% de los nacidos que lo hicieron de madres de esa edad en 1975 y llegan a ser 6,5\% en 1995 . To- 
davía se incrementan más los nacidos de madres con 40 y más años; en esos años el porcentaje de nacidos pasa de ser $0,1 \%$ a ser $1,3 \%$. Como los mecanismos de control de natalidad han aumentado en ese período, debe concluirse que se trata sobre todo de embarazos deseados, deliberados y, por las edades, en su mayoría de mujeres activas; en parte quizá de segundos matrimonios de la mujer o del varón, o de los dos.

A esta creciente natalidad a edades tardías, debe añadirse un fenómeno concurrente, aunque sea de escaso peso estadístico pero revelador de los cambios en las orientaciones culturales de nuestra sociedad. Se trata de la inseminación artificial de mujeres con edades avanzadas y con altos niveles ocupacionales, que exhiben su subsiguiente maternidad en los medios de comunicación. Se trata de una muestra del giro cultural que afecta a la edad de la maternidad, pero más aún de su postergación hasta su acceso estable a altos niveles ocupacionales. Emerge una maternidad voluntaria, a menudo asociada a mujeres con una trayectoria laboral exitosa, que cumplen a continuación su aspiración a tener hijos. Parece que una nueva generación de mujeres posterga sus decisiones reproductivas hasta tener consolidadas sus posiciones laborales.

Hay que señalar que se observa igualmente una tendencia a la homogeneidad en los comportamientos reproductivos de la mujer. En situaciones de tradicionalismo, cuando es muy baja la incorporación -duradera- de la mujer al trabajo extradoméstico, la actividad laboral de la mujer reduce claramente la tasa de natalidad; si se quiere son las pioneras. Pero cuando es baja ya la natalidad de esa sociedad, las pautas de reproducción son mucho menos afectadas por el hecho del trabajo. Y en gran medida esta es la situación que se percibe en España.

En cualquier caso ha de advertirse que la tasa de natalidad requiere examen pormenorizado. En España todos los estudios acreditan que se ha producido un cambio muy importante: históricamente se daba por hecho que nacían más hijos que los deseados, como consecuencia de los fallos en los mecanismos de control. Pero desde la democracia la tendencia es la contraria: nacen menos niños de los que las madres y padres desean. Se trata de una grave situación el que una democracia no permita que se puedan materializar los deseos legítimos de los ciudadanos.

Por otro lado no es el hecho del trabajo -en abstracto- lo que genera efectos en la natalidad. Las diferencias se producen según el tipo, nivel y demás condiciones efectivas del trabajo. Margarita Delgado, analizando los datos de la Encuesta de Fecundidad del INE de 1999, observó consecuencias muy decisivas en relación con la temporalidad del empleo. Su influjo es muy alto. Por ejemplo, en función de la categoría ocupacional, 
el promedio de hijos más bajo $(0,72)$ se produce cuando son ocupados temporales los dos miembros de la pareja. Todavía más: de las seis categorías más bajas respecto a la media de hijos tenidos, en todas al menos un miembro de la pareja es ocupado temporal. Por el contrario, las categorías con media de hijos más altas cuentan con una mujer que se dedica a las labores del hogar o es empresaria autónoma; es decir la mujer dispone de tiempo o flexibilidad para dedicarse a la crianza.

En el fondo de la evolución de las tasas de natalidad -especialmente de las mujeres activas- se encuentra la dificultad de compaginar responsabilidades familiares y laborales. El retraso en la incorporación a la actividad explica que sea ahora cuando la sociedad española deba abordar esta cuestión. España cuenta con notables carencias para facilitar esa compatibilidad en el sistema cultural, en equipamiento y servicios públicos, en vida cotidiana y hasta en comportamientos en las nuevas generaciones poco proclives -o si se quiere poco exigidas-para compartir la realización de tareas domésticas. No podemos examinarlas ahora. Pero se necesita tener presente estas dinámicas para contextualizar el descenso de la natalidad de las mujeres activas y valorarlo debidamente.

Aunque se trata de decisiones personales, los contextos sociales son decisivos para promover u obstaculizar los comportamientos reproductivos de la sociedad. Y en el momento actual es un hecho que el contexto dificulta notablemente la natalidad de las mujeres activas. Las dificultades objetivas son subsanadas por costes personales y familiares. Y en gran medida por el apoyo de la red familiar extensa, de manera especial por los abuelos, que sustituyen a los padres en las tareas de custodia y crianza de sus nietos, hijos de parejas que ambos trabajan. La consistencia de la red familiar de apoyo es muy alta y por completo desconocida fuera de los países latinos. No deja de ser un contrasentido que un paso hacia la modernidad, como la creciente actividad de las mujeres, se posibilite por el afianzamierito de la red familiar extensa. Pero en fin, ya se sabe que el progreso no es nunca lineal y sus sendas son, a menudo, sinuosas.

\section{Trabajo y calidad de la relación}

Los efectos de la incorporación al trabajo extradoméstico no se circunscriben a la natalidad. No se limitan al número de hijos sino a la calidad de las interacciones en el seno del grupo familiar entre la pareja y entre los padres e hijos. 
Los datos disponibles evidencian la alta calidad de las interacciones entre los padres y los hijos. La visión catastrofista o rupturista de las relaciones intergeneracionales, que tantas veces se difunden desde los medios de comunicación, es difícil encontrarle fundamentación empírica en la sociedad española. La sociedad española ha incorporado con una rapidez y profundidad, que ya quisieran otras instituciones sociales, a los cambios radicales en su mismo cimiento familiar. Esta innovación no ha significado una quiebra, sino una readaptación muy exitosa de la vida familiar. Y no solo en las relaciones padres e hijos, sino en las relaciones de pareja.

Las relaciones de pareja se han visto enriquecidas y, a la vez, dificultadas en virtud de la autonomía que ahora tienen los dos miembros de la pareja, en lugar de uno en el pasado. El trabajo de los dos miembros de la pareja permite enriquecer su relación siempre y cuando los elementos de contexto -duración, nivel ocupacional-sean adaptables a esa relación. Pero como ya he apuntado, lo importante no es el hecho de la actividad laboral, sino las condiciones, aspiraciones y satisfacción en relación a la actividad. Si se rechaza el trabajo que se realiza, la frustración puede trasladarse al ámbito doméstico y empeorar la relación.

Pero la actividad laboral tiene una importante consecuencia al facilitar sin duda el divorcio. El salario proporciona una ampliación de los márgenes de libertad y autonomía. Por consiguiente facilita que, si existen tensiones y conflictos, éstas terminen en divorcio. Pero no existen datos que avalen que el divorcio aumente porque la mujer trabaje. Incrementa la autonomía económica para afrontar una perspectiva de ruptura, que en otras condiciones pudiera ser sofocada. Y estos efectos son tan notorios que algunos sociólogos, estoy pensando por ejemplo en B Bastard, destacan que el empleo de la mujer facilita también el planteamiento del divorcio por parte de los maridos. No hay que olvidar que los efectos económicos de las rupturas son importantes y una situación de autonomía económica de la mujer reduce el alcance -económico o temporal- de las consecuencias económicas de la ruptura para el marido.

\section{Trabajo y socialización de los hijos}

Es imposible tratar de una cuestión que requiere por si sólo una monografía. Los efectos del trabajo de la madre y del padre se entremezclan con otros aspectos como la televisión. Es un hecho que no se están produciendo tendencias todo lo positivas que se aspiran en relación al desa- 
rrollo y socialización de los hijos. El alto número de horas dedicadas a contemplar la televisión, sobre todo en las grandes ciudades, puede guardar relación con la disponibilidad de tiempo.

Los padres que los dos trabajan pasan menos tiempo con sus hijos, pero no está demostrada que la calidad de la relación sea inferior. En la socialización de los hijos se están produciendo problemas derivados de un conglomerado de hechos que cristalizan en las crisis de la escuela.

Los efectos del trabajo en el rendimiento académico son igualmente complejos de discernir. No es fácil aislar lo que puedan ser efectos de ese trabajo y los efectos atribuibles, en su caso, a la mejora económica o de oportunidades que los ingresos de ese empleo proporciona. Posiblemente esos efectos sean diferentes cuando se introduce el divorcio que cuando éste es una realidad ya asentada. Y por supuesto los efectos académicos pueden variar sustantivamente en el momento de crisis y con posterioridad.

El alcance real del divorcio en el rendimiento académico de los hijos está sujeto a multitud de dimensiones sin investigar a fondo en España. A lo mejor no son análogos para los hijos y para las hijas. Pero en países con historia dilatada de divorcios, los datos constatan efectos positivos de la participación laboral de la mujer en los resultados educativos de los hijos. Incluso sus efectos positivos son independientes de la educación o de la ocupación del padre, y persiste tanto para las hijas como para los hijos. En qué medida estas tendencias se encuentran en España es imposible determinarlo. Lo único cierto es que la relación se necesita estudiar en profundidad, más allá de una simple relación entre actividad y divorcio. Cada una se encuentra mediatizada por multitud de aspectos -personales, de ciclo vital, sociales, familiares, laborales- que se entrecruzan y ese entrecruce es la biografía particular donde se produce un determinado resultado escolar. Aislar el trabajo y el divorcio para verificar el resultado académico significa mutilar la compleja realidad social.

\section{Trabajo mujer y estado de bienestar}

La creciente realidad del trabajo extradoméstico de los dos miembros de la pareja altera por completo situaciones históricamente muy consolidadas. La familia siempre ha sido el ámbito de protección, acogida y ayuda de sus miembros en situaciones de ancianidad, enfermedad, jubilación, parto, invalidez, desempleo o cualquier otra dificultad sobrevenida. Ese papel se le ha asignado siempre a la familia pero con la peculiaridad 
de que, en realidad, quien asumía su desempeño era, casi en exclusiva, la mujer. La familia era el ámbito, pero la mujer era la persona que ha tenido a su cargo la realización de esas actividades.

Durante mucho tiempo, incluso milenios, existieron condiciones sociales -todo lo discriminatorias que se quiera- que posibilitaban llevar a cabo la tarea. Pero con la incorporación de la mujer a la actividad extradoméstica, cambia por completo la situación: desaparecen las bases sociales que permitían que la familia desempeñara esas actividades de cuidado en el pasado. Hoy ya no hay ningún adulto en permanencia constante en el hogar; la pareja desempeña su jornada fuera del mismo. Ninguna persona con necesidades de cuidado puede permanecer en tal escenario hoy. No es, como muchas veces se argumenta, que aumente el egoísmo; la razón es estructural. Las condiciones actuales de vida dificultan, se quiera o no, el desempeño de actividades de cuidado que terminaban antes desempeñadas en el ámbito de la familia por la mujer.

Los cambios familiares requieren por consiguiente innovaciones en el ámbito de las prestaciones propias del estado de bienestar. En particular, la atención a los mayores es ya una cuestión urgente en nuestra sociedad como consecuencia de la nueva realidad familiar y el descenso de la natalidad, junto a otros muchos factores incluso la mayor movilidad geográfica que puede dificultar aún más la participación de la red familiar en el apoyo de los mayores.

\section{La familia como fuente de empleo}

La situación descrita no solo alude a las dificultades de vida de las familias españolas. En un momento de transición, como nos encontramos, la incorporación ya se ha materializado, pero todavía no los ajustes sociales, organizativos, de servicios y equipamientos públicos que respondan a esa nueva realidad. De ahí la necesidad de desarrollar medidas activas de compatibilidad por parte del sector público.

Pero esas dificultades estructurales convierten a la familia en uno de los principales yacimientos de empleo en estos momentos. Para atender a las necesidades reales de las familias, se crean empleos para hacer frente a sus necesidades. Los servicios a domicilio están ya creando empleo en numerosas dimensiones; los servicios para el acompañamiento y prestación de servicios a personas mayores o discapacitados, servicios a personas enfermas, preparación y distribución de comidas a domicilio, servicios de limpieza y arreglo del hogar, entrega de todo tipo de mer- 
cancías a domicilio etc. Y son muy numerosos también en relación al cuidado de los niños, en una atención regular antes de la escolaridad obligatoria, ocasional o durante las vacaciones con estancias deportivas, de ocio o de estudio. Y además los servicios de atención a quienes están ya en edad escolar, sobre todo con actividades deportivas, culturales, recreativas o de ampliación de estudio. El libro de L. Cachón («Nuevos yacimientos de empleo en España» 1998) ilustra muy bien las potencialidades de creación de empleo derivadas de la transferencia de actividades desempeñadas antes por la familia y las nuevas demandas de calidad de vida y el cambio social están desarrollando.

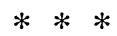

El examen de algunas relaciones entre trabajo de la mujer y familia acredita, ante todo la multiplicidad de sus dimensiones. Los puntos aludidos son tan sólo una corta parcela que requiere atención a otras muchas cuestiones. No hemos examinado, por ejemplo, los efectos en la estructura de toma de decisiones dentro de la familia o en las relaciones de poder en la pareja o en la gestión económica de los bienes familiares. $\mathrm{O}$ en la socialización de los hijos y de las hijas, en la misma realización de las tareas domésticas, donde pueden estarse produciendo desequilibrios más fuertes por razón de generación que por razón de sexo. O incluso tantos aspectos internos del trabajo, como las experiencias de promoción o ascenso, $o$ al revés y tantas otras cuestiones.

Pero, en el fondo, el problema supera claramente las experiencias de las parejas. Lo que se evidencia son las difíciles relaciones entre las responsabilidades familiares y laborales, para varones y mujeres. La sociedad española no está organizada para abordar y resolver cuestiones que otros países -porque iniciaron antes la trayectoria de la incorporación de la mujer al trabajo- tienen mejor resueltas. Y no son solo mecanismos económicos ni de servicios sociales. Son imprescindibles todos pero hay uno que ha de estar presente si se busca la efectividad de cualquier medida material. Me refiero al esfuerzo de mentalización de la sociedad española. Las leyes no cambian la realidad social, por consiguiente no creo en ninguna medida que se funde solo en la introducción de normas legales. Por eso es preciso reordenar aspectos de nuestra vida cotidiana que posibiliten esa compatibilidad sin los costes que se derivan de ello ahora.

Los ritmos temporales de nuestra sociedad deben reordenarse para facilitar las actividades públicas y privadas de las personas. Se convocan actividades y reuniones en España a unas horas que en el resto de Euro- 
pa ya se ha cenado. Las dificultades reales de compatibilidad se encuentran en la trama misma de nuestra vida cotidiana. La jornada partida, los horarios comerciales, los hábitos culinarios dificultan la doble responsabilidad. Bienvenidas pues sean las leyes, pero que no vengan solas. Y además, que arrastren al sector privado. Son fáciles las innovaciones en el sector público. Pero se necesita implicar a las empresas privadas, que vean incluso los beneficios que les pueden reportar las facilidades en la compatibilidad. El bienestar de los trabajadores -y por eso las medidas para la compatibilidad-constituye un componente básico de su rendimiento, además de un derecho inherente a su condición de trabajador y persona con responsabilidades familiares. El impulso de esta compatibilidad es el reto de nuestra sociedad en estos inicios del siglo XXI y una aportación decisiva para el bienestar de los ciudadanos españoles. 